\title{
Use of a towed camera system to investigate benthic habitat use by inter-nesting female hawksbill sea turtles
}

\author{
J. Walcott ${ }^{1, *}$, S. Eckert ${ }^{2}$, H. A. Oxenford ${ }^{3}$, J. A. Horrocks ${ }^{1}$ \\ ${ }^{1}$ Department of Biological and Chemical Sciences, University of the West Indies, Cave Hill Campus, PO Box 64, \\ Bridgetown BB11000, Barbados \\ ${ }^{2}$ Department of Biology and Natural Resources, Principia College, Elsah, IL 62028, USA \\ ${ }^{3}$ Centre for Resource Management and Environmental Studies, University of the West Indies, Cave Hill Campus, PO Box 64, \\ Bridgetown BB11000, Barbados
}

\begin{abstract}
The types of marine benthic habitats utilised by hawksbill sea turtles Eretmochelys imbricata nesting at Needham's Point, Barbados, were investigated using an underwater drop camera. Habitats used preferentially (i.e. those within high-use areas) tended to be high relief and densely covered with biota, characterised by high abundance of hard corals and shallower than less frequented areas. These structurally complex habitats offered opportunities for rest and refuge, but not for foraging, with females showing no preference for sites with high sponge abundance. Females appeared to trade off site quality (i.e. based on benthic relief, cover and species composition) against the energy expended to get there, travelling long distances (up to $21.2 \mathrm{~km}$ ) to higher-quality sites.
\end{abstract}

KEY WORDS: Eretmochelys imbricata $\cdot$ Inter-nesting interval $\cdot$ Benthic habitat use $\cdot$ Underwater video

\section{INTRODUCTION}

With the exception of the leatherback turtle, sea turtles spend the majority of their lives associated with benthic habitats. For example, green turtles associate with sea grass beds (Hays et al. 2002, Ballorain et al. 2010, Stimmelmayr et al. 2010) and hawksbills with coral reef habitats (van Dam \& Diez 1997, Starbird et al. 1999, Scales et al. 2011). For these species, the benthos provides opportunities to rest, take refuge and forage, all of which are critical elements upon which their survival depends. During the breeding season, mature females leave behind the familiarity of their foraging grounds, migrating to nearshore areas in the vicinity of their nesting beach, where they will encounter relatively unfamiliar benthic habitats (Horrocks et al. 2001, Godley et al. 2002,
Storch 2003, Blumenthal et al. 2006). The long period of time between such migrations, 2 to $3 \mathrm{yr}$ for most sea turtle species (Chan \& Liew 1999, Beggs et al. 2007 ), adds to the relative unfamiliarity of these benthic habitats. This is because natural changes brought about by rare natural phenomena such as hurricanes and bleaching events and more common ones such as storm surges, combined with anthropogenic impacts such as coastal development, overexploitation by fisheries of nearshore keystone species and physical damage of marine habitats, can all have significant and irreversible impacts on the marine environment over short periods of time (see Alvarez-Filip et al. 2009). The benthic environment encountered during one breeding season may therefore not be the same as that experienced in another season. 
Although the stay of gravid females in these nearshore habitats is relatively short (i.e. 2 to $3 \mathrm{mo}$; Bell \& Parmenter 2008, Hart et al. 2010) compared to the intervening years in their traditional foraging grounds, it is a critical time for these animals, as they must conserve energy to lay 4 to 5 clutches of eggs during the breeding season (see Walcott et al. 2012, 2013). It is therefore predicted that optimal habitats should be selected and utilised over the course of the shortterm residency at breeding grounds. Whether females feed during this period appears to vary according to species and location (e.g. Tucker \& Read 2001, Hays et al. 2002, Cheng et al. 2013). Analysis of dive profiles has suggested that inter-nesting females around Barbados do not feed (Walcott et al. 2013). However, the habitats they use should provide refuge and resting opportunities adequate to support the animals during the process of egg development. For instance, the length of the inter-nesting interval, which is at least partly dependent on the rate of egg development, is affected by water temperature (Schofield et al. 2009, Walcott et al. 2013), and this may be a determining factor in influencing bottom depths used by gravid females. Identification of the key ecological features that characterise benthic habitats used by gravid females is therefore of the utmost importance in the management and protection of sea turtle breeding areas.

During its juvenile and adult life stages, the hawksbill sea turtle Eretmochelys imbricata displays a strong affinity for coral reef habitats (Meylan 1988, Witt et al. 2010), and this is true for juvenile and adult hawksbills around Barbados (see Krueger et al. 2011, Walcott et al. 2012, 2013). Coral reefs are some of the most diverse ecosystems in the marine environment, both in terms of community composition (e.g. hard coral-dominated versus gorgonian- or sponge-dominated) and structural framework (ranging from low to high relief). Hawksbills are believed to feed predominantly on reef-associated sponges throughout much of their range (Meylan 1988, Troëng et al. 2005). Studies suggest that only certain species of sponges are actually preyed upon and that selection is determined to a great extent by local sponge species abundance (León \& Bjorndal 2002, Scales et al. 2011). Hawksbills visibly resemble their surroundings, and the outline of an animal can be effectively disguised once it is lodged into the reef. The structural complexity of the reef environment will therefore determine the opportunities for refuge (Rincon-Diaz et al. 2011) from predators such as bull and tiger sharks. Further, ledges and overhangs provide opportunities for assisted resting, allowing animals to fill their lungs at the surface and use ledges to counter their buoyancy at depths. Fewer ascents for gaseous exchange can minimise energy expenditure, and presumably also the risk of predation (Houghton et al. 2003, Blumenthal et al. 2009, Stimmelmayr et al. 2010, Walcott et al. 2013). Particular ledge locations may also confer thermoregulatory benefits (Stimmelmayr et al. 2010) and cleaning opportunities (Sazima et al. 2004), derived from microhabitats found within reef environments.

Both at foraging and breeding grounds, many species of sea turtles exhibit a high level of in-water site fidelity within and between breeding seasons (Godley et al. 2002, Broderick et al. 2007, Hart et al. 2012, Walcott et al. 2012), suggesting that habitat selection is not random and that some degree of benefit accompanies re-using of the same habitats. Hawksbill females were shown to use the same in-water resident areas (RAs) during each inter-nesting interval within a nesting season, and females in different nesting seasons utilised overlapping areas (see Walcott et al. 2012), suggesting that certain parts of the reef may have preferred characteristics. Female hawksbills nesting in the first few months of the breeding season in Barbados arrive from their foraging grounds before most nesters do, and would presumably face less competition for preferred inter-nesting habitats closer to the nesting beach. Interestingly, some of the most experienced hawksbill females (i.e. those that had already nested in multiple nesting seasons) occupied internesting habitats farthest from the nesting beach (see Walcott et al. 2012), suggesting that these areas may offer some particularly important characteristics that outweigh the energetic costs of travel to reach them. Competition may also come from the foraging population of juvenile hawksbills that resides year-round on the reef (Krueger et al. 2011). However, the smaller size of these animals would likely increase the range of possible sites available to them for rest and refuge, thereby reducing competition between them and the larger adult females that only occupy Barbados waters during the breeding season. Schofield et al. (2006, 2007) reported that inter-nesting female loggerheads engaged in behaviours ranging from passive threat displays to aggressive sparring on $>75 \%$ of occasions when an intruder entered the visual range of a resident female. This supports the suggestion that competition between females can occur over optimal sites for refuge.

The aims of this study were to investigate the species composition, structural cover and relief of resident areas used by gravid females and, through comparison of core or high-use areas with less used areas 
within the RA, to better understand the basis of female inter-nesting habitat choice. We tested predictions that (1) females will establish RAs in areas where relief and cover are highest (high-quality sites), conferring best opportunities for resting and camouflage, (2) that the high-use areas (HUAs) within the RAs will be of higher quality than other sites within the RAs, (3) that, if females do feed during the inter-nesting interval, RAs will be more likely to be located in areas of high sponge availability, (4) that females will trade off habitat quality against energy expended in travel, such that more distant RAs will be of higher quality, and finally (5) that earlier arriving females and/or larger females will occupy the highest-quality habitats, due to the greater availability of sites to occupy and/or to larger females being better defenders of sought-after spaces on the reef.

\section{MATERIALS AND METHODS}

\section{Study site}

Needham's Point beach, Barbados $\left(13^{\circ} 04^{\prime} 41.33^{\prime \prime} \mathrm{N}\right.$, $\left.59^{\circ} 36^{\prime} 32.69^{\prime \prime} \mathrm{W}\right)$, was used as the site for deployment and retrieval of tracking equipment (see Walcott et al. 2012). Located to the southwest of the island (Fig. 1), in the vicinity of the estuary of the Constitution River that runs through the capital city Bridgetown, the $1.5 \mathrm{~km}$ stretch of beach provides nesting habitat for $>25 \%$ of the island's nesting hawksbills annually (Horrocks 1992, Beggs et al. 2007). The study site encompassed the nearshore marine environment of the south coast of Barbados. Characterised by a narrow insular shelf, with the $200 \mathrm{~m}$ isobath lying 2 to $3 \mathrm{~km}$ offshore (Lewis \& Oxenford 1996, Krueger et al. 2011), the shelf consists of different forms of coral habitats including coral rubble, patch reefs and a bank reef most seaward, extending along much of the coastline. Patch reefs range in depth from 6 to $15 \mathrm{~m}$, and the bank reef from 15 to $40 \mathrm{~m}$. Depths reach as much as 40 to $55 \mathrm{~m}$ between the 2 reefs, and this deep habitat consists mainly of sand (Lewis \& Oxenford 1996).

The benthic composition of patch and bank reefs differs along this coast. Both reef types are hard coraldominated, with the abundance of reef-associated organisms (i.e. hard corals, gorgonians and sponges) being higher on the bank than on patch reefs (UWI 2008). Patch reefs also have lower structural complexity and are dominated by encrusting weedy

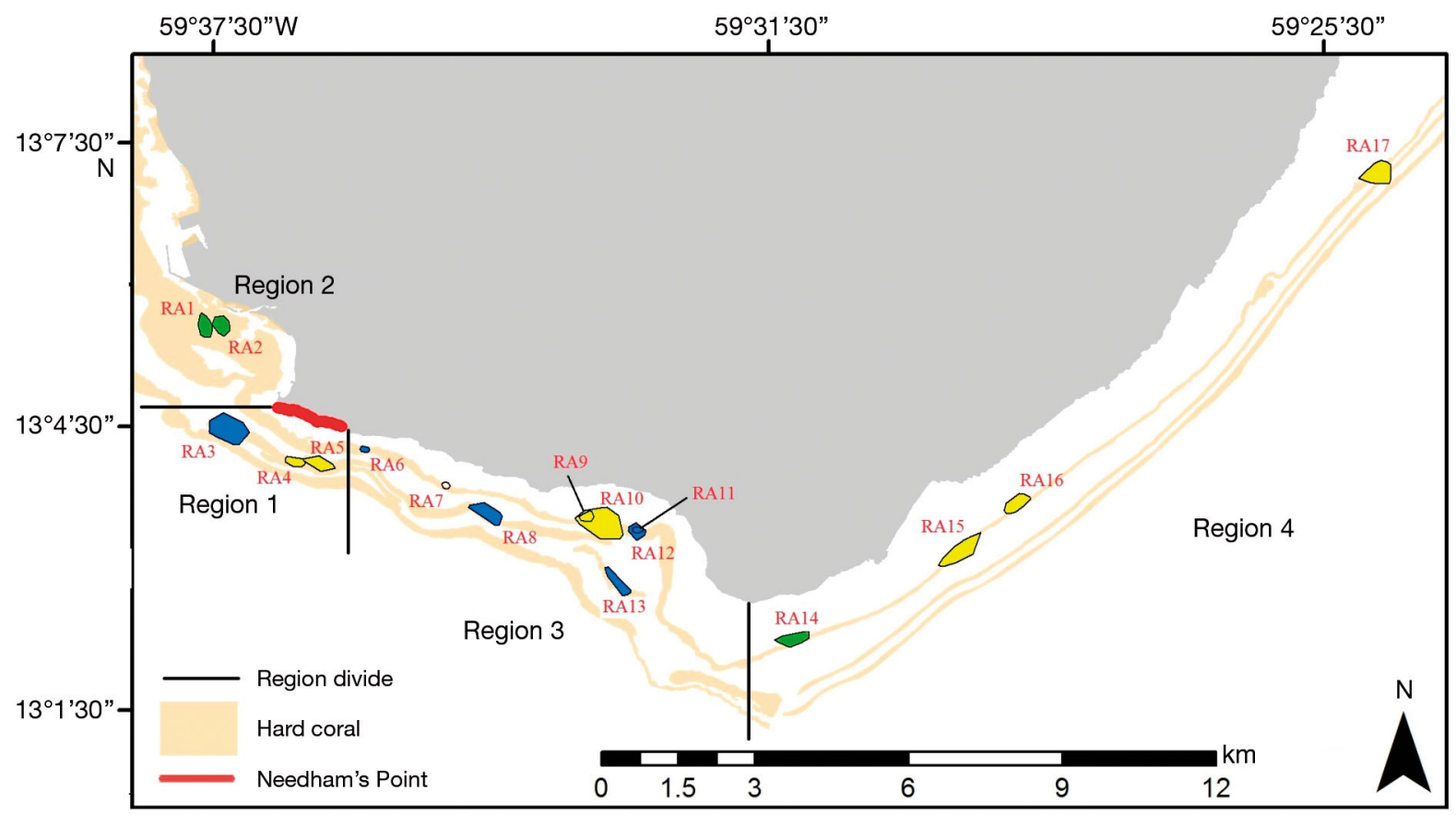

Fig. 1. Southern portion of Barbados, showing the nesting beach of hawksbill sea turtles Eretmochelys imbricata (Needham's Point), the resident areas (RAs, coloured polygons) utilised by study animals ( $\mathrm{n}=17$ ) and the hard coral reef system. Yellow, blue and green polygons represent high-, medium- and low-quality RAs, respectively. The 4 regions indicating different distances from the nesting beach are also shown. Benthic habitat data provided by the Barbados Coastal Zone Management Unit, Ministry of Environment and Drainage 
corals (i.e. rapidly growing, small colonies that are short-lived and quickly replaced) such as Agaricia spp. and Porites spp., whereas the bank reef is structurally complex and dominated by the frameworkbuilding corals (i.e. massive species with slower growth rates) such as Montastrea spp. and Diploria spp.; UWI 2008, Alvarez-Filip et al. 2009). Many species of sponges ( $>50$ species) are also present, including Sidonops neptuni (formerly Geodia neptuni) which has been reported as a preferred prey species for the foraging population of juvenile hawksbills around Barbados (see Krueger et al. 2011) and elsewhere (León \& Bjorndal 2002).

\section{Data collection}

During the 2008 to 2010 nesting seasons, a sample of hawksbills emerging onto Needham's Point beach to nest were outfitted with GPS dataloggers, providing spatial data for 17 animals (see Walcott et al. 2012). For details on individual selection criteria and equipment used see Walcott et al. $(2012,2013)$. Walcott et al. (2012) focused primarily on the alongshore movement patterns of gravid females during internesting intervals, while Walcott et al. (2013) focused on their diving behaviour during various stages of the inter-nesting interval. Data collected revealed the use of spatially restricted nearshore areas, termed RAs, by each study animal (see Walcott et al. 2012). RAs represented the spatially restricted areas where animals spent the majority ( $>50 \%$ ) of the internesting interval, and were delineated as minimum convex polygons using the Home Range Tools for ArcGIS® version 1.1. RAs were all located along the south coast of the island, ranged from 0.7 to $21.2 \mathrm{~km}$ away from the nesting beach and showed a close association with the hard coral reef system (Walcott et al. 2012; Fig. 1).

Using ArcGIS 9.2 (ESRI), a $100 \times 100 \mathrm{~m}$ grid was overlaid on each of the previously defined RAs, and intersects were subsequently used as sample sites to survey. Underwater video surveys were conducted by means of an underwater drop camera (Sea Viewer 950) functioning as a towed camera. The number of sample sites per RA varied depending on the size of the RA, and included sites both within and outside of the HUAs of RAs. HUAs were defined as core areas of activity within the RA and were calculated using the $50 \%$ kernel density estimation (KDE) and, similar to other studies (see Makowski et al. 2006, Seney \& Landry 2008, Hart et al. 2010, 2012, Schofield et al. 2010, Blanco et al. 2012), were delineated using the
Home Range Tools for ArcGIS extension (Rodgers \& Kie 2011) and the fixed-kernel least-squares crossvalidation smoothing factor (hcv) for each KDE (Seaman \& Powell 1996). When the variance of $x$ - and $y$-coordinates of each recorded position was highly unequal, the data were rescaled before applying the kernel method. The sites sampled within each of the RAs (i.e. determined by the intersects of the grid overlay) did not always fall within the delineated HUAs. This occurred with 5 RAs, allowing HUA data from only 10 RAs to be used for analysis.

The underwater colour video drop camera used was a Sea Viewer 950 with a wide-angle lens that illuminated its surroundings with a light-emitting diode (LED) light ring (www.seaviewer.com). Two minutes of video footage of the benthic habitat at each survey site were collected between May 2011 and January 2012. A comparison of biological assessment of the south coast bank reef off Barbados in 2012 showed little inter-annual difference in hard coral cover, soft corals and sponges from the previous assessment in 2007, suggesting that changes in ecological characteristics were not likely between the years of the tracking and the year of the habitat assessment (UWI 2014). The camera itself was rated to a depth of $305 \mathrm{~m}$ but was outfitted with a SeaSerpent ${ }^{\mathrm{TM}}$ Marine Cable which provided a maximum scope of $61 \mathrm{~m}$ depth. The camera was mounted in a PVC frame, which provided stability once deployed and ensured that a constant pan view $\left(45^{\circ}\right.$ angle above the substrate) was filmed at all sites. The drop cam was deployed from a drifting vessel, and colour video recording began as soon as the pre-selected grid intercept was reached. The intercept positions were located using a handheld GPS Garmin $72 \mathrm{H}$ unit. Video clips were recorded directly and stored on a PMC-700R digital video recorder with a 7 -inch $(17.8 \mathrm{~cm})$ thin-film-transistor liquid-crystal display (TFT LCD) screen in MPEG4 video format at $720 \times$ 480 resolution. Video clips were subsequently downloaded onto a computer and analysed.

\section{Data analysis}

To capture the highest-quality benthic footage, only the middle portion of each 2 min video clip (i.e. from 0:30 to 1:30 min) was used for analysis. Each 1 min segment was viewed on a large screen (diagonal length: $196 \mathrm{~cm}$ ) for visual assessment. Benthic habitats at all survey sites were scored by 1 or more observers based on (1) benthic characteristics and (2) benthic species composition. 
Benthic characteristics scored were relief (i.e. vertical height) and cover (i.e. the extent to which sand was covered with biotic habitat). Relief of coral habitats tends to be correlated with structural complexity (i.e. the presence of holes, ledges and overhangs), with higher relief usually translating to greater architectural complexity (Alvarez-Filip et al. 2009). Benthic cover can be used to gauge the potential for camouflage for the animals. Based on the extent of relief and degree of cover, the benthic characteristics at each survey site were scored simultaneously and categorised as: (1) low relief and sparse cover, (2) low relief and dense cover, (3) high relief and sparse cover, or (4) high relief and dense cover (Fig. 2a). All of the scored survey sites within an RA were then used to determine the predominant characteristics of the RA itself. Survey sites and RAs falling into the category 'high relief and dense cover' were considered as 'high-quality habitat', those with high relief and sparse cover or low relief and dense cover were considered 'medium quality', and those with low relief and sparse cover were 'low quality'.

Benthic species composition (Fig. 2b) was assessed based on the relative abundance of major taxonomic groups thought to be of most importance to hawksbills (i.e. hard corals, gorgonians and erect sponges). Hard corals and gorgonians were considered important because of their structural complexity and relief which could provide sites for refuge, and sponges because they may provide foraging opportunities. Although hawksbills are known to eat both encrusting and erect sponges (León \& Bjorndal 2002), erect sponges were chosen for scoring due to the ease of visual identification on the video footage, and the

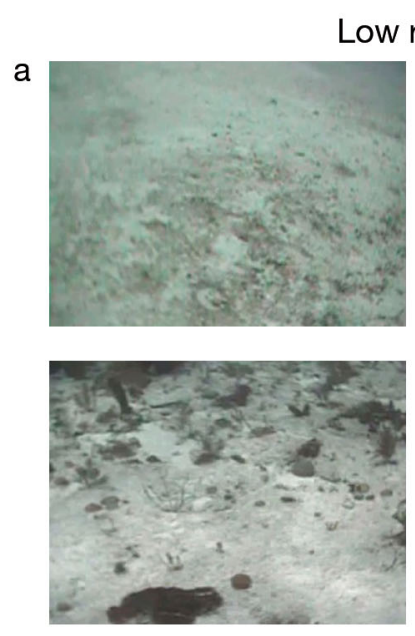

sparse

b

Hard corals \& sponges (erect)

\section{Gorgonians}

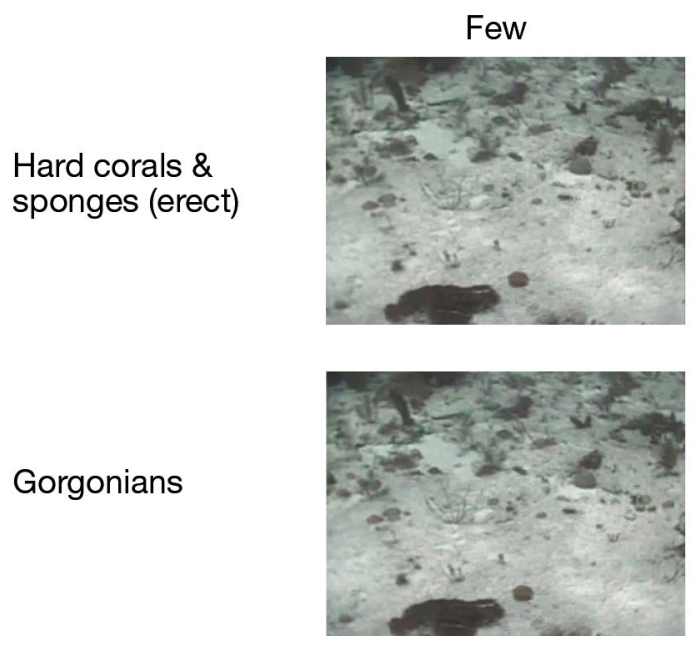

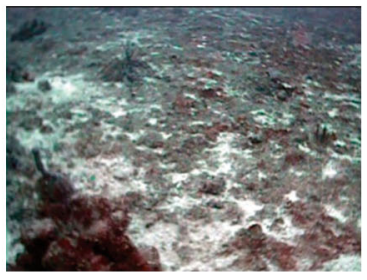

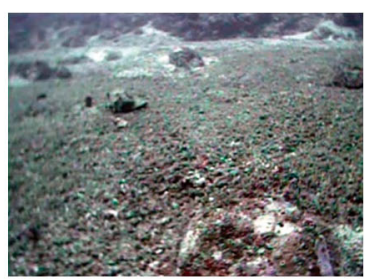

dense

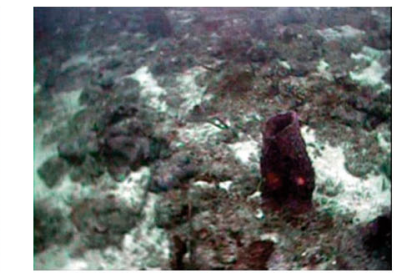

sparse
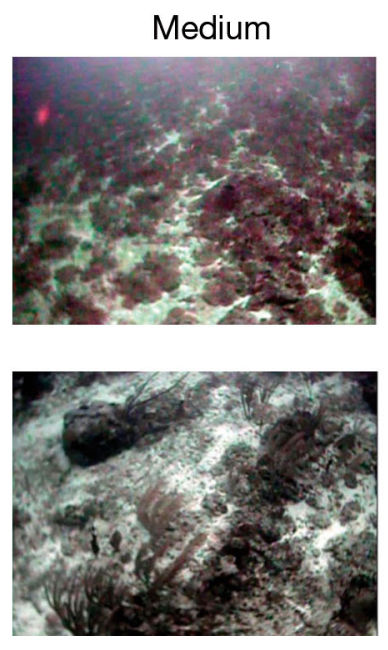

Fig. 2. Photo key of drop cam video excerpts showing typical appearance of the various benthic habitats encountered by study animals. (a) Benthic characteristics (relief and cover) and (b) benthic species composition (for each of the key taxonomic groups) 
fact that a preferred prey sponge species, $S$. neptuni, has an erect form. Relative abundance of each of the 3 taxonomic groups was scored using a rating scale: 0 - none, 1 - few, 2 - medium, and 3 - frequent (see Fig. 2 for examples of habitats at each level of the rating scale). Survey sites were categorised based on the predominant taxonomic group (i.e. the most frequently observed of hard corals, gorgonians or sponges). Each of the assigned categories was treated the same regardless of the actual scores; for example, a hard coral-dominated site where hard corals received a score of 3 was not distinguished from one where the hard corals received a score of 2 or 1 but were still the dominant taxonomic group.

A random subsample of the videos (10\%) was independently scored by 2 additional observers (experienced marine scientists with extensive knowledge of the reefs around Barbados) to check for agreement in habitat assessments. An inter-rater reliability analysis using the weighted Kappa statistic was performed to determine consistency among scorers and was found to be in substantial agreement (weighted Kappa =0.64). Benthic characteristics and composition data were subsequently analysed using SPSS 17.0 for Windows. RAs were described according to the relief-cover category and the relative abundance of different taxonomic groups that the majority of survey sites sampled within the RA fell into. Similarly, the characteristics and composition of benthic habitats within the HUAs were compared to those outside of the HUAs.

Habitat quality and species composition of RAs were examined in relation to distance from the nesting beach and depth, and in relation to day of year of first nesting and size of females. Given that the RAs described spanned 3 nesting seasons, they were assigned into 1 of 3 periods of the nesting season (early: May-June, middle: July-August, late: September-October) based on the date (day of year) they were first occupied, and their locations into 1 of 4 regions based on their proximity to the nesting beach (i.e. Region 1: $\leq 1 \mathrm{~km}$, Region 2: 1 to $\leq 2 \mathrm{~km}$, Region 3 : 2 to $\leq 5 \mathrm{~km}$, Region 4: $>5 \mathrm{~km}$, Fig. 1) for the purposes of the analyses below. The benthic characteristics of survey sites within HUAs were compared to those in the lesser used parts of the RA to investigate whether there were differences that might explain why females chose the RAs that they did.

Where data failed testing for normality and no significant difference was seen after log transformation, non-parametric test statistics were reported. However, means and standard deviations were also given to allow for direct comparison with previous studies.

\section{RESULTS}

The video surveys carried out at 206 intersection points in the 17 inter-nesting RAs (mean \pm SD: $13.7 \pm$ 10.7 survey sites per RA) provided a total of $412 \mathrm{~min}$ of video footage of which 206 min were used for analysis. There were 2 instances where the RA of a study animal in one nesting season completely engulfed that used by another female in a different nesting season (i.e. RAs 9 and 10 and RAs 11 and 12; Fig. 1). In both cases, data were used for the bigger of the 2 RAs (i.e. RAs 10 and 12) to avoid replication of data, resulting in the analysis of 15 RAs (Table 1). The area of benthic habitat covered at each survey site was not identical, but was influenced by depth and by the surface and bottom currents experienced at each survey site.

The majority of survey sites within RAs $(68.0 \%$; $n=$ 206) included some amount of coral reef habitat; the majority had dense cover (76.3\%), while $49.6 \%$ were of high relief. The remaining sites were bare sand, categorised as low relief and sparsely covered and devoid of any of the scored benthic species and at greater depths $(38 \pm 11 \mathrm{~m})$ than the reef habitat survey sites (32 $\pm 15 \mathrm{~m}$; Mann-Whitney $U$-test, $\mathrm{N}_{1}=139$, $\mathrm{N}_{2}=67, \mathrm{p}<0.05$ ), where $\mathrm{N}_{1}$ represents the number of survey sites with coral reef habitat and $\mathrm{N}_{2}$ the number with bare sand. Of the sites that contained reef habitat $(\mathrm{n}=139)$, most $(50.4 \%)$ were at depths that corresponded with the bank reef (15-40 m), 16.6\% were at depths corresponding with patch reefs $(<15 \mathrm{~m})$, and $33.1 \%$ were at depths corresponding with deeper reef habitat $(>40 \mathrm{~m})$.

Benthic composition of reef habitats within survey sites fell into 5 distinct categories: (1) habitats with an even distribution of hard corals, gorgonians and erect sponges (wide diversity), (2) habitats dominated by 2 of the 3 taxa; usually hard corals and gorgonians (moderate diversity), (3) habitats dominated by hard corals (hard coral-dominated), (4) habitats dominated by gorgonians (gorgoniandominated) and (5) habitats dominated by sponges (sponge-dominated) (Table 2). Most survey sites with reef present $(34.5 \%, \mathrm{n}=139)$ were characterised as wide diversity, followed by hard coraldominated $(30.9 \%)$, while the smallest number of sites, and the deepest, were sponge-dominated $(5.8 \%)$ (Table 2$)$. The majority of sites within each of the above 5 benthic species composition categories had dense benthic cover, but not necessarily high relief (Table 2). Only hard coral- and gorgoniandominated sites were predominantly high relief (Table 2). 
Table 1. Summary of benthic habitat data for each resident area (RA; $\mathrm{n}=15$ ) of hawksbill sea turtles Eretmochelys imbricata nesting in Barbados. Benthic species composition categories are shown in Table 2. For each RA, the benthic characteristics and species composition observed most frequently throughout all of the survey sites for that RA were used to describe the RA.

Depth is given as mean \pm SD. CCL: curved carapace length; HUA: high-use area; na: not applicable; nd: no data

\begin{tabular}{|c|c|c|c|c|c|c|c|c|c|c|c|}
\hline $\begin{array}{l}\text { Turtle } \\
\text { ID }\end{array}$ & $\begin{array}{l}\text { CCL } \\
(\mathrm{cm})\end{array}$ & $\begin{array}{l}\text { Nesting } \\
\text { period }\end{array}$ & RA & Region & $\begin{array}{l}\text { Depth } \\
\text { (m) }\end{array}$ & $\begin{array}{l}\text { Area } \\
\left(\mathrm{km}^{2}\right)\end{array}$ & $\begin{array}{c}\text { Benthic cl } \\
\text { Relief }\end{array}$ & $\begin{array}{l}\text { acteristics } \\
\text { Cover }\end{array}$ & $\begin{array}{l}\text { Benthic spp. } \\
\text { composition }\end{array}$ & $\begin{array}{l}\text { No. survey } \\
\text { sites }\end{array}$ & $\begin{array}{l}\text { HUA area } \\
\left(\mathrm{km}^{2}\right)\end{array}$ \\
\hline T08 & 87.3 & Early & 1 & 2 & $23 \pm 7$ & 0.09 & Low & Sparse & 3 & 9 & 0.011 \\
\hline T18 & 93.1 & Early & 2 & 2 & $22 \pm 8$ & 0.07 & Low & Sparse & 2 & 5 & 0.013 \\
\hline T15 & 90.6 & Late & 3 & 1 & $42 \pm 6$ & 0.31 & Low & Dense & 3 & 31 & 0.081 \\
\hline T13 & 90.2 & Mid & 4 & 1 & $34 \pm 10$ & 0.06 & High & Dense & 3 & 6 & 0.007 \\
\hline T22 & - & Mid & 5 & 1 & $40 \pm 9$ & 0.05 & High & Dense & 3 & 11 & 0.015 \\
\hline $\mathrm{T} 11$ & 93.7 & Early & 6 & 3 & $12^{\mathrm{a}}$ & 0.02 & High & Sparse & 4 & 1 & 0.002 \\
\hline T02 & 96.9 & Early & 7 & 3 & $20 \pm 8$ & 0.01 & $n a^{b}$ & $n a^{b}$ & 3 & 3 & 0.003 \\
\hline $\mathrm{T} 21$ & 92.0 & Mid & 8 & 3 & $52 \pm 7$ & 0.15 & Low & Dense & 5 & 16 & 0.031 \\
\hline T04 & 89.3 & Early & 10 & 3 & $28 \pm 13$ & 0.40 & High & Dense & 3 & 40 & 0.035 \\
\hline T09 & 93.0 & Early & 12 & 3 & $29 \pm 12$ & 0.07 & High & Sparse & 3 & 8 & 0.020 \\
\hline T14 & 90.8 & Mid & 13 & 3 & $52 \pm 6$ & 0.10 & Low & Dense & 3 & 12 & 0.021 \\
\hline T19 & 100.0 & Early & 14 & 4 & $20 \pm 12$ & 0.09 & Low & Sparse & 2 & 12 & 0.005 \\
\hline T12 & 93.1 & Mid & 15 & 4 & $36 \pm 10$ & 0.22 & High & Dense & 3 & 22 & 0.007 \\
\hline T10 & 92.8 & Early & 16 & 4 & $18 \pm 6$ & 0.12 & High & Dense & 3 & 10 & 0.002 \\
\hline T16 & 92.5 & Mid & 17 & 4 & $28 \pm 12$ & 0.20 & High & Dense & 3 & 20 & 0.025 \\
\hline
\end{tabular}

Based on the hypothesis that relief and benthic cover are indicators of habitat quality for hawksbills, 6 RAs were categorised as high quality (i.e. high relief and dense cover), 5 as medium quality (i.e. high relief and sparse cover or low relief and dense cover) and 3 as low quality (i.e. low relief and sparse cover) (Table 3). High-quality RAs were all hard coral- dominated, compared to only $33 \%$ in the low-quality RAs (Table 3). The majority of high-quality RAs were located within Region 4 (i.e. on the more distant southeast coast; Fig. 1), such that although not significant, the mean distance travelled by females to high-quality RAs $(9.2 \pm 8.2 \mathrm{~km})$ tended to be greater than that travelled to medium or low-quality RAs

Table 2. Benthic species composition of reef habitats observed throughout the resident area (RA) survey sites ( $\mathrm{n}=139)$ and their corresponding benthic characteristics. Depth is given as mean $\pm \mathrm{SD}$

\begin{tabular}{|c|c|c|c|c|c|c|c|c|}
\hline \multirow{3}{*}{$\begin{array}{l}\text { Cate- } \\
\text { gory }\end{array}$} & \multirow{3}{*}{$\begin{array}{l}\text { Benthic species } \\
\text { composition }\end{array}$} & \multirow{3}{*}{$\begin{array}{l}\text { Depth } \\
\text { (m) }\end{array}$} & \multirow{3}{*}{$\begin{array}{l}\text { Survey } \\
\text { sites (n) }\end{array}$} & \multirow{3}{*}{$\begin{array}{l}\text { Frequency } \\
\qquad(\%)\end{array}$} & \multicolumn{4}{|c|}{ Benthic characteristics } \\
\hline & & & & & $\longrightarrow \mathrm{Re}$ & ief - & $\longrightarrow \mathrm{Cov}$ & er $\longrightarrow$ \\
\hline & & & & & Low $(\%)$ & High (\%) & Sparse $(\%)$ & Dense $(\%)$ \\
\hline 1 & Wide diversity & $34 \pm 15$ & 48 & 34.5 & 58.3 & 41.7 & 31.3 & 68.7 \\
\hline 2 & Moderate diversity & $30 \pm 13$ & 21 & 15.1 & 61.9 & 38.1 & 23.8 & 76.2 \\
\hline 3 & Hard coral-dominated & $32 \pm 14$ & 43 & 30.9 & 46.5 & 53.5 & 13.9 & 86.1 \\
\hline 4 & Gorgonian-dominated & $23 \pm 17$ & 19 & 13.7 & 42.1 & 57.9 & 26.3 & 73.7 \\
\hline 5 & Sponge-dominated & $42 \pm 12$ & 8 & 5.8 & 75.0 & 25.0 & 25.0 & 75.0 \\
\hline
\end{tabular}

Table 3. Summary of resident area (RA) characteristics by designated RA quality ( $\mathrm{n}=14)$. HC: hard coral, CCL: curved carapace length of resident female hawksbill sea turtles Eretmochelys imbricata. Depth and area values are given as means \pm SD. For regions see Fig. 1

\begin{tabular}{|lccccccc|}
\hline Quality & $\begin{array}{c}\text { RA } \\
(\mathrm{n})\end{array}$ & $\begin{array}{c}\text { Depth } \\
(\mathrm{m})\end{array}$ & $\begin{array}{c}\text { Area } \\
\left(\mathrm{km}^{2}\right)\end{array}$ & $\begin{array}{c}\text { HC-dominated } \\
(\%)\end{array}$ & $\begin{array}{c}\text { Mean } \\
\text { CCL }(\mathrm{cm})\end{array}$ & $\begin{array}{c}\text { Region most } \\
\text { frequently observed }\end{array}$ & Nesting period \\
\hline Low & 3 & $21.7 \pm 1.5$ & $0.08 \pm 0.01$ & 33 & 93.5 & 2 & 3 \\
Medium & 5 & $37.4 \pm 17.1$ & $0.13 \pm 0.11$ & 60 & 92.0 & Early \\
High & 6 & $30.1 \pm 7.8$ & $0.18 \pm 0.13$ & 100 & 91.6 & Early, mid, late \\
Early, mid
\end{tabular}


$(4.0 \pm 2.8 \mathrm{~km}$ and $4.8 \pm 4.9 \mathrm{~km}$, respectively; KruskalWallis test, $p>0.05$ ). No significant differences were detected among the 3 quality categories for RAs with respect to either depth of the RA, or area of the RA (Kruskal-Wallis test, $\mathrm{p}>0.05$ for all cases). There was no correlation between date of first nesting (day of year) and the relief of the RA that a female occupied (Spearman rank correlation, $r=-0.08, p>0.05$ ); however, there was a positive correlation with benthic cover (Spearman rank correlation, $\mathrm{r}=0.537, \mathrm{p}<$ 0.05 ), with densely covered RAs being used more often later in the season. There was no difference in mean size of females utilising the 3 habitat quality categories across the entire season (Kruskal-Wallis test, $\mathrm{p}>0.05, \mathrm{n}=13$ ).

A total of 24 survey sites fell within the HUAs of the RAs, offering the opportunity to compare habitat characteristics of the RA between the core areas most frequently used by the females (HUAs) with those less frequently used. HUAs ranged in size from 0.002 to $0.081 \mathrm{~km}^{2}(\mathrm{n}=10)$ and in depth from 16 to $50 \mathrm{~m}$ (mean: $32.1 \pm 12.4 \mathrm{~m}, \mathrm{n}=10$ ). Mean HUA depth $(32.1 \mathrm{~m})$ was shallower than mean depth of the sites outside of the HUAs $\left(35.5 \pm 12.0 \mathrm{~m}_{\text {; }}\right.$ paired $t$-test, $\mathrm{p}<$ $0.05, \mathrm{n}=10$ ). Although there was no correlation between mean depth of RA and RA area (Spearman rank correlation, $r=0.385, p>0.05$ ), deeper RAs had larger HUAs (Spearman rank correlation, $r=0.726$, $\mathrm{p}<0.05)$. The majority $(87.5 \%, \mathrm{n}=24)$ of survey sites within HUAs comprised reef habitat, and $70 \%$ of the HUAs were hard coral-dominated (Table $4 ; \mathrm{n}=10$ HUAs). In terms of benthic cover, $83.3 \%$ of the survey sites in HUAs $(\mathrm{n}=24)$ had dense cover; a significantly higher percentage than across all other RA survey sites $\left(\chi^{2}=5.9, \mathrm{p}<0.05, \mathrm{n}=206\right)$. In terms of

Table 4. Comparison of resident area (RA) habitat characteristics found at survey sites within ( $\mathrm{n}=24$ sites) and outside $(\mathrm{n}=182)$ of the high-use areas. Benthic species abundances are based on the means of individually scored survey sites using the rating scale: 0 - none, 1 - few, 2 - medium and 3 - frequent (see 'Materials and methods'). Values are means \pm SD

\begin{tabular}{|lcc|}
\hline Parameter & Inside & Outside \\
\hline Mean depth $(\mathrm{m})$ & $32.1 \pm 12.4$ & $35.5 \pm 12.0$ \\
Abundance score & & \\
Hard coral & $2.2 \pm 0.8$ & $1.6 \pm 0.8$ \\
Gorgonian & $1.6 \pm 0.8$ & $1.5 \pm 0.8$ \\
Sponges & $1.6 \pm 0.7$ & $1.4 \pm 0.8$ \\
Predominant benthic & High relief with & Low relief with \\
characteristics & dense cover & dense cover \\
& (High quality) & (Medium quality) \\
Benthic species composition & Hard coral- & Hard coral- \\
& dominated & dominated \\
\hline
\end{tabular}

relief, $45.8 \%$ of HUA sites had high relief $(\mathrm{n}=24)$ compared to $31.9 \%$ across all other RA sample sites $(\mathrm{n}=182)$, but the difference was not significant $\left(\chi^{2}=\right.$ $1.9, \mathrm{p}>0.05, \mathrm{n}=206)$. Comparison of sites within and outside of HUAs revealed that no significant difference existed between the 2 categories with respect to abundance of hard corals, gorgonians and sponges (Wilcoxon signed ranks test, $\mathrm{p}>0.05, \mathrm{n}=10$; Table 4). Both categories were hard coral-dominated; however, sites within HUAs were predominantly high relief with dense cover, while those outside were low relief with dense cover (Table 4).

No adult or juvenile turtles were observed during the drop cam recording sessions, although adult females are typically regularly seen during the breeding season (May to October) and juveniles year round by SCUBA divers. Adult females are rarely seen swimming in the open, but are most often well hidden under ledges (Fig. 3). The camouflage offered by coral reefs or the movement of animals away from the approaching drop cam may explain why sea turtles were not observed in the videos.

\section{DISCUSSION}

As air-breathing aquatic animals or 'surfacers' (Kramer 1988, see also Kooyman 1989), most species of sea turtle rely heavily on benthic marine habitats throughout the majority of their lives (Houghton et al. 2003, Ballorain et al. 2010, Stimmelmayr et al. 2010), and identification of the benthic habitats used during the reproductive phase is therefore particularly important for management and conservation of endangered sea turtle species. In this study, underwater video recording by drop camera was used to conduct surveys of benthic habitats used by gravid hawksbills around Barbados (see Vandermeulen 2007, Walker et al. 2008 for examples of its use in ground-truthing benthic habitat data). This means of visual assessment is considered as effective as other more conventional survey methods (e.g. line and belt transects) for the collection of high-quality data (see Carleton \& Done 1995, Wilson et al. 2007), while providing the additional benefits of allowing data to be collected from marine habitats too deep for SCUBA divers, thereby increasing researcher safety, as well as providing a permanent record of 

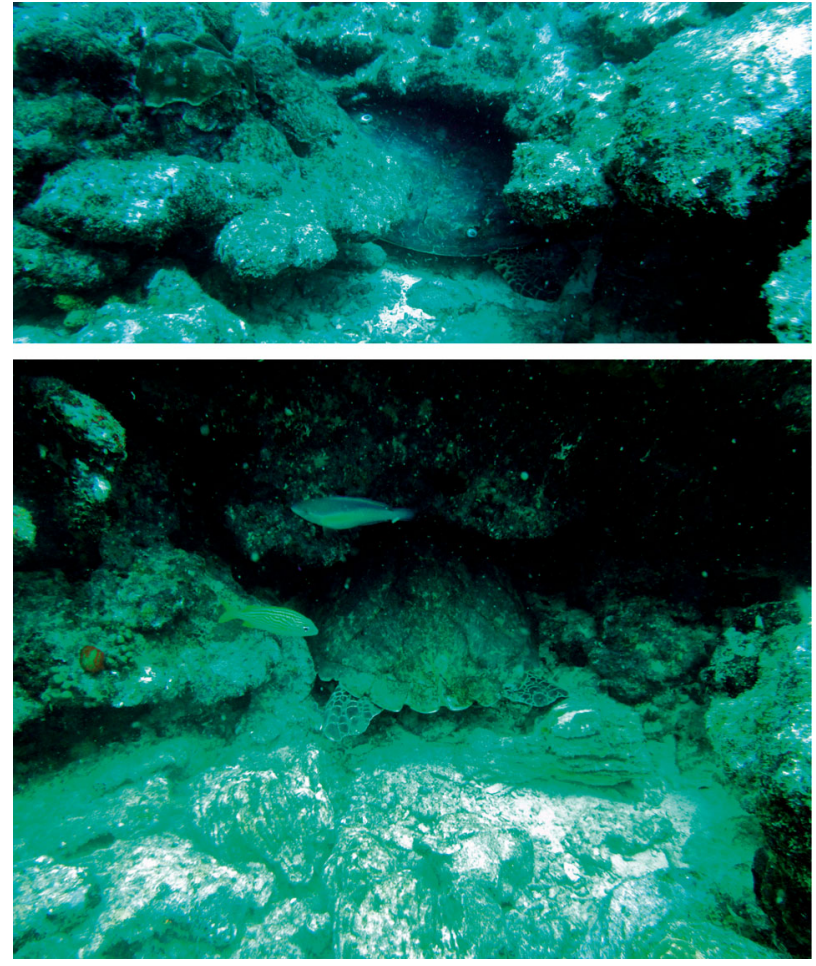

Fig. 3. Examples of gravid female hawksbill sea turtles Eretmochelys imbricata in Barbados utilising ledges and overhangs within the bank reef ecosystem during diurnal periods of the inter-nesting interval (source: Barbados Sea Turtle Project)

areas surveyed. Animal-borne video cameras, effectively used for habitat assessment in other species (e.g. Seminoff et al. 2006, Okuyama et al. 2013), were not considered for this study because of the potential for equipment to be dislodged by males attempting to mate or by the actions of the females themselves as they moved within the reef.

Hard coral-dominated reef habitats can be classified as critical inter-nesting habitat for gravid hawksbills nesting in Barbados, as has been similarly described for hawksbills nesting at Buck Island (US Virgin Islands) in the northern Caribbean (Storch 2003). The predominance of this habitat type within RAs, and particularly within the HUAs, reinforces the close association between hawksbills and reef habitats during the nesting season that has already been widely observed at foraging grounds in the Caribbean (van Dam \& Diez 1997, Houghton et al. 2003, Blumenthal et al. 2009). Not only have movements away from and towards the nesting beach been found to closely adhere to the coral reef system (Walcott et al. 2012), but the majority of the inter-nesting interval was also spent within RAs dominated by hard coral reef habitat at depths (15-40 m) consistent with the bank reef. Given that the areas beyond the coral reef habitats were generally composed of bare sand and were deeper, we suggest that use of the shallower reef ecosystem could increase protection from predators through the camouflage and refuge opportunities provided, minimise energy expenditure through shorter travel distances to the surface for gaseous exchange (Walcott et al. 2013) and perhaps provide cues for orientation as well as opportunities for foraging.

Most RAs established by study animals were of high quality $(42.9 \%)$, having both high relief and dense cover, or of medium quality $(35.7 \%)$, having either high relief or dense cover. The high percentage of high-quality RAs on the southeast coast bank reef suggested that females may trade off the expense of travel distance for habitat quality. RAs were rarely established on low relief and sparsely covered habitat, and 2 out of 3 times they were close to the nesting beach. Females spent most of their time in the shallower HUAs of their RAs where cover, and to a lesser extent relief, were higher than in areas outside of the HUAs. Occupation of densely covered and structurally complex habitats may provide key microhabitats where females can avoid predators (see also Blumenthal et al. 2009) and the advances of adult males seeking to mate, whilst also providing opportunities for assisted resting (Houghton et al. 2003, Blumenthal et al. 2009, Stimmelmayr et al. 2010, Rincon-Diaz et al. 2011).

Despite being an energetically expensive period, several factors suggested that the availability of foraging habitat was not a determining factor in the selection of RAs. Earlier arriving females have previously been shown to take up residence in shallower RAs (Walcott et al. 2012), where sponges are rare, while few females took up residence in deep, sponge-dominated habitats identified in this study. The overall low abundance of erect sponges within RAs, even deep RAs, suggested that, if it did occur, foraging during the inter-nesting period would be time- and energy consuming. Deeper RAs did have larger HUAs, but the predominant use of U-shaped dives associated with resting, the lack of depth variation seen in the bottom phase of dives (a feature present during periods of active foraging), and the lack of diel variation in diving by study animals across all dive depths while in their RAs (see Walcott et al. 2013) suggest that this was not because they were foraging. Our results indicate that inter-nesting hawksbills around Barbados are not foraging; instead they rely on fat reserves built up at foraging grounds prior to nesting (see also van Dam et al. 2008, Santos et al. 2010). 
The distribution of RAs along the south coast of Barbados spanned a total distance of $23.4 \mathrm{~km}$, greater than that reported from other breeding grounds where gravid females usually remained in the close vicinity of the nesting beach (e.g. for green turtles: Dizon \& Balazs 1982, Hays et al. 1999, Blanco et al. 2012; but see Richardson et al. 2013; loggerheads: Zbinden et al. 2007, Hart et al. 2010; hawksbills: Starbird et al. 1999). If dense cover and high relief were the only factors affecting habitat choice, females nesting at the beginning of the breeding season when the availability of high quality habitat would presumably be greater, might be expected to establish RAs only on high-quality sites, especially those closer to the nesting beach. However, we found no evidence of this. Moreover, larger females were no more likely to occupy high-quality sites than were smaller females. Previous work has shown that females do not switch between RAs during the course of a nesting season (Walcott et al. 2012), and there is evidence for repeated use of the same internesting habitats from season to season in other species (see Limpus \& Reed 1985, Marcovaldi et al. 2010). None of these observations would be expected if females were comparing the qualities of their existing RAs to those of others.

We therefore propose that the females that make up this high-density nesting colony establish their RAs on habitat that meets some baseline critical habitat quality, but which is also influenced by the distance from other females, perhaps to avoid the energetic costs of competitive interactions with other females (Schofield et al. 2006, 2007), and also the advances of adult males, who may be attracted to locations where densities of females are high. Indeed, around Barbados, gravid females are very solitary, often wedged head first under overhangs and ledges (J. Walcott pers. obs.). This tendency to minimise interaction would also explain the large area over which inter-nesting habitats are spread, the finding that RAs occupied when female density is highest (i.e. July-August; Beggs et al. 2007) are characterised by greater cover than RAs settled early or late in the season, and the previously reported rarity of RAs in the vicinity of the nesting beach where large numbers of females gather for up to several days before emerging onto the nesting beach (see Walcott et al. 2012). Females residing in deeper RAs may benefit from less frequent encounters with other females or males, but incur the cost of fewer structural features for rest or refuge. This reduced level of site fixity to particular ledges or overhangs may explain their larger HUAs.
The conservation and management of coral reefs is of utmost importance for sustained population recovery of hawksbills in the Caribbean region. Given the importance of reef habitat for refuge and assisted resting during the inter-nesting period, the significant declines being detected in hard coral abundance and species diversity (Gardner et al. 2003, Jackson et al. in press) and in structural complexity (Alvarez-Filip et al. 2009) are of considerable concern for sea turtle conservation (see also Troëng et al. 2005). In Barbados, the bank reef still appears to offer habitat of a quality that suits gravid hawksbills. However, increased local efforts to ensure that critical sea turtle habitats are better protected in the future will be essential if the recovery of the hawksbill turtle around Barbados is to continue in the face of the growing threats to reefs and nesting beaches from increasing coastal settlement and climate change.

Acknowledgements. This study would not have been possible without the funding received from the Barbados Tourism Development Corporation, the Marine Turtle Conservation Fund (United States Fish and Wildlife Service) and the University of the West Indies (Office of Research). We especially thank Renata Goodridge (CERMES, UWI), Stephen Bourne and Vanroy Jordan (fishermen), the Barbados Sea Turtle Project Field Director (Dr. Darren Browne) and volunteers, and Dr. Henri Valles, Caroline Gooding, Shelly-Ann Cox and Myles Phillips (Centre for Resource Management and Environmental Studies, UWI) for various contributions during the course of the study. Work was conducted under permits from the Fisheries Division of the Ministry of Agriculture and Rural Development.

\section{LITERATURE CITED}

Alvarez-Filip L, Dulvy NK, Gill JA, Cote IM, Watkinson AR (2009) Flattening of Caribbean coral reefs: region-wide declines in architectural complexity. Proc R Soc Lond B Biol Sci 276:3019-3025

Ballorain K, Ciccione S, Bourjea J, Grizel H, Enstipp M, Georges J (2010) Habitat use of a multispecific seagrass meadow by green turtles Chelonia mydas at Mayotte Island. Mar Biol 157:2581-2590

$>$ Beggs JA, Horrocks JA, Krueger BH (2007) Increase in hawksbill sea turtle Eretmochelys imbricata nesting in Barbados, West Indies. Endang Species Res 3:159-168

Bell IP, Parmenter JC (2008) The diving behavior of internesting hawksbill turtles, Eretmochelys imbricata (Linnaeus 1766), on Milman Island Reef, Queensland, Australia. Herpetol Conserv Biol 3:254-263

Blanco GS, Morreale SJ, Seminoff JA, Paladino FV, Piedra R, Spotila JR (2012) Movements and diving behavior of internesting green turtles along Pacific Costa Rica. Integr Zool 8:293-306

Blumenthal JM, Solomon JL, Bell CD, Austin TJ and others (2006) Satellite tracking highlights the need for international cooperation in marine turtle management. Endang Species Res 2:51-61 
Blumenthal JM, Austin TJ, Bothwell JB, Broderick AC and others (2009) Diving behavior and movements of juvenile hawksbill turtles Eretmochelys imbricata on a Caribbean coral reef. Coral Reefs 28:55-65

> Broderick AC, Coyne MS, Fuller WJ, Glen F, Godley BJ (2007) Fidelity and over-wintering of sea turtles. Proc R Soc Lond B Biol Sci 274:1533-1539

> Carleton JH, Done TJ (1995) Quantitative video sampling of coral reef benthos: large-scale application. Coral Reefs 14:35-46

Chan EH, Liew HC (1999) Hawksbill turtles, Eretmochelys imbricata, nesting on Redang Island, Terengganu, Malaysia, from 1993 to 1997. Chelonian Conserv Biol 3:326-329

Cheng IJ, Bentivegna F, Hochscheid S (2013) The behavioural choices of green turtles nesting at two environmentally different islands in Taiwan. J Exp Mar Biol Ecol 440:141-148

Dizon AE, Balazs GH (1982) Radio telemetry of Hawaiian green turtles at their breeding colony. Mar Fish Rev 44: $13-20$

Gardner TA, Cote IM, Gill JA, Grant A, Watkinson AR (2003) Long-term region-wide declines in Caribbean corals. Science 301:958-960

Godley BJ, Richardson S, Broderick AC, Coyne MS, Glen F, Hays GC (2002) Long-term satellite telemetry of the movements and habitat utilisation by green turtles in the Mediterranean. Ecography 25:352-362

> Hart KM, Zawada DG, Fujisaki I, Lidz BH (2010) Internesting habitat-use patterns of loggerhead sea turtles: enhancing satellite tracking with benthic mapping. Aquat Biol 11:77-90

> Hart KM, Sartain AR, Fujisaki I, Pratt HL Jr, Morley D, Feeley MW (2012) Home range, habitat use, and migrations of hawksbill turtles tracked from Dry Tortugas National Park, Florida, USA. Mar Ecol Prog Ser 457:193-207

- Hays GC, Luschi P, Papi F, del Seppia C, Marsh R (1999) Changes in behaviour during the inter-nesting period and post-nesting migration for Ascension Island green turtles. Mar Ecol Prog Ser 189:263-273

> Hays GC, Glen F, Broderick AC, Godley BJ, Metcalfe JD (2002) Behavioural plasticity in a large marine herbivore: contrasting patterns of depth utilisation between two green turtle (Chelonia mydas) populations. Mar Biol 141: 985-990

Horrocks JA (1992) WIDECAST Sea Turtle Recovery Action Plan for Barbados. In: Eckert KL (ed) CEP Technical Report No. 12. UNEP Caribbean Environment Programme, Kingston

Horrocks JA, Vermeer LA, Krueger BH, Coyne M, Schroeder BA, Balazs GH (2001) Migration routes and destination characteristics of post-nesting hawksbill turtles satellite tracked from Barbados, West Indies. Chelonian Conserv Biol 4:107-114

Houghton JDR, Callow MJ, Hays GC (2003) Habitat utilization by juvenile hawksbill turtles (Eretmochelys imbricata, Linnaeus, 1766). J Nat Hist 37:1269-1280

Jackson J, Cramer K, Donovan M, Lam V (eds) (2013) Status and trend of Caribbean coral reefs 1969-2012. Global Coral Reef Monitoring Network (GCRMN), Townsville

Kooyman GL (1989) Diverse divers: physiology and behavior. Springer-Verlag, Berlin

Kramer DL (1988) The behavioral ecology of air breathing by aquatic animals. Can J Zool 66:89-94

Krueger BH, Chaloupka MY, Leighton PA, Dunn JA, Horrocks JA (2011) Somatic growth rates for a hawksbill population in coral reef habitat around Barbados. Mar Ecol Prog Ser 432:269-276

León YM, Bjorndal KA (2002) Selective feeding in the hawksbill turtle, an important predator in coral reef ecosystems. Mar Ecol Prog Ser 245:249-258

Lewis JB, Oxenford HA (1996) A field guide to the coral reefs of Barbados. Department of Biology, McGill University, Montreal, QC

Limpus CJ, Reed PC (1985) The loggerhead turtle, Caretta caretta, in Queensland: observations on internesting behaviour. Aust Wildl Res 12:535-540

> Makowski C, Seminoff JA, Salmon M (2006) Home range and movements of juvenile Atlantic green turtles (Chelonia mydas L.) on shallow reef habitats in Palm Beach, Florida, USA. Mar Biol 148:1167-1179

Marcovaldi MÂ, Lopez GG, Soares LS, Lima EHSM, Thomé JCA, Almeida AP (2010) Satellite-tracking of female loggerhead turtles highlights fidelity behavior in northeastern Brazil. Endang Species Res 12:263-272

> Meylan A (1988) Spongivory in hawksbill turtles: a diet of glass. Science 239:393-395

> Okuyama J, Kana N, Takuji N, Satoko K and others (2013) Ethogram of immature green turtles: behavioral strategies for somatic growth in large marine herbivores. PLoS ONE 8:e65783

Richardson PB, Broderick AC, Coyne MS, Ekanayake L and others (2013) Satellite telemetry reveals behavioural plasticity in a green turtle population nesting in Sri Lanka. Mar Biol 160:1415-1426

> Rincon-Diaz MP, Diez CE, van Dam RP, Sabat AM (2011) Effect of food availability on the abundance of juvenile hawksbill sea turtles (Eretmochelys imbricata) in inshore aggregation areas of the Culebra Archipelago, Puerto Rico. Chelonian Conserv Biol 10:213-221

Rodgers AR, Kie JG (2011) HRT: Home Range Tools for ArcGis - draft August 10, 2011. Centre for Northern Forest Ecosystem Research, Thunder Bay, ON

> Santos AJB, Freire EMX, Bellini C, Corso G (2010) Body mass and the energy budget of gravid hawksbill turtles (Eretmochelys imbricata) during the nesting season. J Herpetol 44:352-359

Sazima I, Grossman A, Sazima C (2004) Hawksbill turtles visit moustached barbers: cleaning symbiosis between Eretmochelys imbricata and the shrimp Stenopus hispidus. Biota Neotrop 4:1-6

Scales KL, Lewis JA, Lewis JP, Castellanos D, Godley BJ, Graham RT (2011) Insights into habitat utilisation of the hawksbill turtle, Eretmochelys imbricata (Linnaeus, 1766), using acoustic telemetry. J Exp Mar Biol Ecol 407: 122-129

Schofield G, Katselidis KA, Dimopoulos P, Pantis JD, Hays GC (2006) Behaviour analysis of the loggerhead sea turtle Caretta caretta from direct in-water observation. Endang Species Res 2:71-79

Schofield G, Katselidis KA, Pantis JD, Dimopoulos P, Hays GC (2007) Female-female aggression: structure of interaction and outcome in loggerhead sea turtles. Mar Ecol Prog Ser 336:267-274

Schofield G, Bishop CM, Katselidis KA, Dimopoulos P, Pantis JD, Hays GC (2009) Microhabitat selection by sea turtles in a dynamic thermal marine environment. J Anim Ecol 78:14-21

Schofield G, Hobson VJ, Lilley MKS, Katselidis KA, Bishop CM, Brown P, Hays GC (2010) Inter-annual variability in the home range of breeding turtles: implications for cur- 
rent and future conservation management. Biol Conserv 143:722-730

Seaman DE, Powell RA (1996) An evaluation of the accuracy of kernel density estimators for home range analysis. Ecology 77:2075-2085

Seminoff JA, Jones TT, Marshall GJ (2006) Underwater behaviour of green turtles monitored with video-timedepth recorders: What's missing from dive profiles? Mar Ecol Prog Ser 322:269-280

Seney EE, Landry AM Jr (2008) Movements of Kemp's ridley sea turtles nesting on the upper Texas coast: implications for management. Endang Species Res 4:73-84

Starbird CH, Hills-Starr Z, Harvey JT, Eckert SA (1999) Internesting movements and behavior of hawksbill turtles (Eretmochelys imbricata) around Buck Island Reef National Monument, St. Croix, U.S. Virgin Islands. Chelonian Conserv Biol 3:237-243

Stimmelmayr R, Latchman V, Sullivan M (2010) In-water observations of Hawksbill (Eretmochelys imbricata) and Green (Chelonia mydas) Turtles in St. Kitts, Lesser Antilles. Mar Turtle Newsl 127:17-19

Storch S (2003) The behaviour of immature and female hawksbill turtles (Eretmochelys imbricata) at sea. PhD dissertation, University of Kiel

Troëng S, Dutton PH, Evans D (2005) Migration of hawksbill turtles Eretmochelys imbricata from Tortuguero, Costa Rica. Ecography 28:394-402

Tucker AD, Read MA (2001) Frequency of foraging by gravid green turtles (Chelonia mydas) at Raine Island, Great Barrier Reef. J Herpetol 35:500-503

UWI (University of the West Indies) (2008) The Barbados Coral Reef Monitoring Programme. Changes in coral reef communities on the west and south coasts 1997-2007. Prepared for the Government of Barbados, Bridgetown

Editorial responsibility: Jeffrey Seminoff,

La Jolla, California, USA
UWI (University of the West Indies) (2014) The Barbados Coral Reef Monitoring Programme. Changes in coral reef communities on the west and south coasts 2008-2012. Prepared for the Government of Barbados, Bridgetown

> van Dam RP, Diez CE (1997) Diving behavior of immature hawksbill turtles (Eretmochelys imbricata) in a Caribbean reef habitat. Coral Reefs 16:133-138

van Dam RP, Diez CE, Balazs GH, Colón Colón LA, McMillan WO, Schroeder B (2008) Sex-specific migration patterns of hawksbill turtles breeding at Mona Island, Puerto Rico. Endang Species Res 4:85-94

Vandermeulen H (2007) Drop and towed camera systems for ground-truthing high frequency sidescan in shallow waters. Can Tech Rep Fish Aquat Sci 2687:1-18

> Walcott J, Eckert S, Horrocks JA (2012) Tracking hawksbill sea turtles (Eretmochelys imbricata) during inter-nesting intervals around Barbados. Mar Biol 159:927-938

Walcott J, Eckert S, Horrocks JA (2013) Diving behaviour of hawksbill turtles during the inter-nesting interval: strategies to conserve energy. J Exp Mar Biol Ecol 448:171-178

Walker BK, Riegl B, Dodge RE (2008) Mapping coral reef habitats in southeast Florida using a combined technique approach. J Coast Res 24:1138-1150

Wilson SK, Graham NAJ, Polunin NVC (2007) Appraisal of visual assessments of habitat complexity and benthic composition on coral reefs. Mar Biol 151:1069-1076

> Witt MJ, McGowan A, Blumenthal JM, Broderick AC and others (2010) Inferring vertical and horizontal movements of juvenile marine turtles from time-depth recorders. Aquat Biol 8:169-177

Zbinden JA, Aebischer A, Margaritoulis D, Arlettaz R (2007) Insights into the management of sea turtle internesting area through satellite telemetry. Biol Conserv 137: $157-162$

Submitted: September 25, 2013; Accepted: February 27, 2014 Proofs received from author(s): May 13, 2014 